\title{
Memória do excesso: vivência do deslocamento compulsório pela Hidrelétrica de Tucuruí
}

\section{Memory of the excess: living of compulsory displacement by Tucuruí Hydroelectric}

Jorge Augusto Santos das Mercês - Doutorando em Ciências Socioambientais, pelo Programa de Pós-Graduação em Desenvolvimento Sustentável do Trópico Úmido (PPGDSTU) no Núcleo de Altos Estudos Amazônicos da UFPA. E-mail: jorge.a.s.merces@gmail.com.

Fábio Fonseca de Castro - Doutor em Sociologia, pela Universidade da Sorbonne (Paris V Descartes). Professor da Universidade Federal do Pará. E-mail: fabio.fonsecadecastro@ gmail.com.

Voyner Ravena Cañete - Doutora em Ciências Socioambientais, pelo Programa de PósGraduação em Desenvolvimento Sustentável do Trópico Úmido (PPGDSTU), Universidade Federal do Pará (UFPA), 2005. Professora Associada I da Universidade Federal do Pará. E-mail: ravenacanete@gmail.com.

\section{Resumo}

Neste artigo descrevemos as narrativas mnemônicas sobre o deslocamento compulsório sofrido por pessoas atingidas pela implantação da Usina Hidrelétrica de Tucuruí no Rio Tocantins (Pará). Nosso objetivo é compreender os sentidos atribuídos às temporalidades localmente denominadas Breu Velho e Novo Breu por meio de metodologia etnográfica com execução de observação participante e entrevistas semiestruturadas e conversas informais com pessoas que viveram o deslocamento compulsório. Funcionando como referente da ausência da forma de vida nos lugares inundados pelo enchimento do lago artificial da usina, Breu Velho denomina a reapresentação de uma demanda por habitar que o Novo Breu não consagra devido ao excesso do evento, que rompeu as expectativas e inabilitou as dinâmicas sociais que conferiam segurança ao ambiente pela conformação de ser-no-mundo negligenciado pela inversão que a ontologia ocidental faz da pessoa.

\section{Palavras-chave}

Memória. Deslocamento Compulsório. Hidrelétrica de Tucuruí. Temporalidades.

\begin{abstract}
In this article we describe the mnemonic narratives about the compulsory displacement suffered by people affected by the implementation of the Tucuruí Hydroelectric Power Plant in the Tocantins River (Pará). Our objective is to understand the meanings attributed to temporalities locally denominated Breu Velho and Novo Bren through ethnographic methodology with execution of participant observation and semistructured interviews and informal conversations with people who have lived the compulsory displacement. Functioning as a reference of the absence of the way of life in the places flooded by the filling of the artificial lake of the plant, Bren Velho denominates the restatement of a demand to inhabit that the Novo Bren does not consecrate due to the excess of the event, that broke the expectations and disabled the dynamics social conditions that conferred security on the environment by the being-in-theworld conformation neglected by the inversion that the Western ontology makes of the person.
\end{abstract}

\section{Keywords}

Memory. Compulsory Displacement. Tucuruí Hydroelectric Plant. Temporalities. 


\section{INTRODUÇÃO}

Iniciar a escrita de uma história implica definir um ponto de partida que se prolonga nas linhas que a descrevem, embora, talvez, nunca saibamos com certeza por onde começar. Este começo antecipa o fim e nos predispõe a ele: não há quem inicie uma história, seja quem conta ou quem a lê ou a ouve, que não espere pelo seu encerramento. É uma atividade que, por ocorrer em uma duração, toma tempo das partes engajadas em seu acontecimento e, assim, ao tocar à realidade no tempo que ocorre "abre-nos outro que dela se desprende" (NUNES, 2013, p. 15); ou seria o que a ela confere justamente a sensação de ser real? Mais grave ainda: como começar uma história para a qual não há perspectiva de haver um final?

De encontro aos fantasmas que animam a memória de deslocados compulsoriamente em 1984 (uma data que não é começo) pela implantação da Usina Hidrelétrica de Tucuruí (UHE-Tucuruí), talvez em direção ao desencontro da encruzilhada do tempo físico com o tempo cronológico $^{1}$ em favor da imersão pragmática e ficcional que "liga entre si momentos que o tempo real separa" (NUNES, 2013, p. 25) - na região do lago de Tucuruí, o Breu Velho pisa os calcanhares de Breu Branco no devir da memória de pessoas atingidas como reassentados, mesmo passados trinta e quatro anos do marco desta história que se inicia, às vezes, antigamente:

é reconhecido por todos os camponeses que a construção da barragem inaugura um outro período em suas vidas. A rigor, as histórias de vida são reportadas em dois períodos: o antigamente e o hoje. O hoje diz respeito a situação atual vivenciada, e tem como marco inicial a construção da barragem (MAGALHÃES, 2007, p. 160).

A pesquisa em campo aconteceu de forma intermitente ao longo de um ano em tipo etnográfico nas cidades de Tucuruí e Breu Branco, com o objetivo de compreender como as pessoas que sofreram o deslocamento compulsório em razão da implantação da hidrelétrica supracitada vivenciam este acontecimento. Como desdobramento da questão inicial nos importou saber quais as reminiscências que conformam uma intersubjetividade comum que confere algum sentido de unidade ao grupo de atingidos, bem como destacar o modo

Segundo Benedito Nunes (2013, p. 23, grifos do autor), o tempo real possui diversas formas, nas quais "se entrecruzam a objetividade do tempo físico com a sucessão regular do presente ao passado e do presente ao futuro do tempo cronologico" 
pelo qual este sentido é, em cada momento, construído por meio de uma forma narrativa mnemonicamente elaborada, pois há a prevalência do agora e assim da ação na significação das coisas da memória, afinal elas ressurgem "em um presente mais rico que o da intuição sensível [...], em um presente de iniciativa" (RICCEUR, 2007, p. 134).

\section{REAPARIÇÃO}

O aviso, e a lição, nos são dados na primeira conversa:

- Eu comparo o Breu Velho com esse Breu novo, assim... (ÚRSULA²).

Não há outro meio de falar do Breu Velho sem que se refira ao Novo Breu, e vice-versa. Assim, todas as entrevistas (gravadas e não gravadas), conversas informais e observações em campo remetiam, em consenso local, uma temporalidade à outra, entre as quais as narrativas de nossos interlocutores transitavam sempre em um sentido comparativo. A comunhão da ausência de algo, daquele tudo [que] foi para o fundo (como dizem lá) com o enchimento do Lago de Tucuruí, traz, pela narração da memória - ora arquivada em suportes técnicos (bypomnesis), ora fugidia, repentina e pouco nítida (anamnesis) $)^{3}$-, ao momento da narrativa a "presença do ausente anteriormente encontrado" (RICCEUR, 2007, p. 56).

Há pessoas que contam esta história, que põem em palavras a vivência pelo evento a partir de uma memória de testemunho. A estas pessoas não foram sugeridos por nós novos papéis com pedidos de assinatura em uma linguagem que elas não praticam, elas já viveram muito isso e não têm boas lembranças das consequências (como veremos). Assim sendo, não utilizamos seus nomes de batismo; identificaremos nossos principais interlocutores por nomes fictícios a partir de uma comparação exagerada com Cem anos de solidão (MÁRQUEZ, 2014):

2 O anonimato quanto ao nome dos interlocutores é guardado através de pseudônimos, como mais à frente, no próprio texto, será explicado.

3 Fábio Castro (2016) sintetiza Derrida ao descrever duas formas de ocorrência do fenômeno mnemônico: a) sob a influência de um objeto que desencadearia a memória, embasada em um referente específico, seja (como ocorre no Novo Breu) um arquivo de fotografias, algumas telhas reutilizadas do lugar que se quer lembrar etc.; e, b) pelo ressurgimento "de um instante esquecido, uma espécie de êxtase, com o qual o passado fala ao presente, revelando-se repentinamente (CASTRO, 2016, p. 191). Ainda com base em Castro (2016), destacamos que a distinção entre as formas $a$ e $b$ não são reciprocamente excludentes. A hypomnesis lembra a obrigatoriedade de lembrar, guardando o referente da lembrança pelos significados que tenta evitar que the escapem, enquanto a anamnesis assombraria estes significados pela realidade da ocorrência que escapa às coisas. Toda bypomnesis é antecipada pela anamnesis que ela tenta conter, e toda anamnesis é, em partes, circunscrita por um referente que mantém a dinâmica da memória. 
assim como os lugares que foram para o fundo do lago de Tucuruí, Macondo foi devastada em nome do progresso. Além da semelhança contextual, os narradores da história do deslocamento compulsório ${ }^{4}$ permitem algumas comparações com alguns personagens do romance:

a) Úrsula: autora de uma pergunta tão assertiva a ponto de a interrogação ao final não fazer jus à convicção do argumento. Ela alega, comparando o Breu Velho com o Novo Breu, que a vida "é assim mesmo. A pessoa vai diminuindo, né?”. Paralelamente, quando Úrsula (do romance) foi enterrada, aconteceu em uma "caixinha um pouco maior que a cestinha em que Aureliano tinha sido levado [quando bebê]" (MÁRQUEZ, 2014, p. 369).

b) José Arcádio: é assombrado pelo fantasma de seu (ainda vivo) rival político, o Alemão. Toda narrativa de José Arcádio se articula na diferença entre ele e aquele, sendo, cada um, a personificação de uma temporalidade inaugurada pelo evento. Semelhante ao que ocorre em Gabriel García Márquez (2014): Prudêncio Aguiar, como assombração, persegue o personagem homônimo à pessoa que anima José Arcádio deste artigo.

c) Rebeca: todas as suas histórias são narradas com uma perspectiva de dentro de casa, como se ela tivesse ficado aprisionada ali desde que casou. A perspectiva de Rebeca na narrativa sobre a qual mantenho atenção assemelha-se ao destino de Rebeca (MARQUEZ, 2014), que, casada com José Arcádio (filho do José Arcádio que empresta seu nome ao nosso interlocutor nesta pesquisa), deixa de viver os espaços públicos até o dia de sua morte.

d) Maurício Babilônia: assim como Maurício Babilônia (MÁRQUEZ, 2014), não costuma falar muito (comigo). Em Cem anos de solidão o personagem quase não tem falas próprias, sendo sempre apresentado pelas interpretações feitas sobre ele pelos membros da família Buendía. Além disso, Maurício Babilônia é um dos únicos personagens racializados no romance de García Márquez (um dos filhos do capitão Aureliano também o é).

Como a memória, a forma deste artigo é, em partes, rizomática, portanto as notas de rodapé funcionam tanto como tradicionalmente se usa, para explicar algum detalhe que não haveria porque estar no corpo do texto, como também para indicar ramificações da malha argumentativa, que não poderia manter o

4 Escolhidos entre os entrevistados pela constância com que se disponibilizavam a conversar sobre o tema desta pesquisa em comparação com aqueles mais esquivos. 
sentido acadêmico sem elas, embora possa preservar a inteligibilidade da história que se pretende contar. Assim, além dos desvios, há, raras vezes, desvios em desvios (notas de rodapé em notas de rodapé) que indicam este acontecimento de derivação da narrativa mnemônica que não o seria sem o rizoma que lhe confere forma.

Retomando: "presença do ausente anteriormente encontrado" (Este artigo, p. 3; apud RICCEUR, 2007, p. 56): foi tornado ausente o ambiente com o qual as pessoas que sofreram o deslocamento compulsório habitavam. Em determinado momento de 1972, o Comitê Organizador dos Estudos Energéticos da Amazônia (ENERAM) concluiu relatório sobre o potencial de geração de energia elétrica na região, apontando local propício para esta utilização em um trecho do rio Tocantins, próximo a Tucuruí. Não obstante as vantagens do lugar para este fim, havia um inconveniente: pessoas; sobretudo pessoas, porque este problema não se resolve sem complicações com algo "simples" como uso de agente laranja ${ }^{5}$. O Estado interveio novamente, desta vez para garantir sua intenção de intervenção anterior. Optou por uma política ineficaz de reassentamento involuntário para os atingidos nos lugares que iriam, à época, para o fundo das águas que foram o rio.

Mais de um paradigma civilizatório entrelaçaram suas linhas no lugar, com ontologias diferentes e inconciliáveis; afinal, ou se mantinha o rio como beira (e todas suas derivações relacionais, das quais também deriva a beira), ou ele seria levado, com tudo mais, para o fundo. Assim, entre uma forma de vida que pressupunha, como alega Francisco Costa (2012, p. 253) sobre o campesinato extrativista amazônico, a manutenção da "natureza originária" para sua existência e outra que se realiza pela "transformação tensa" (COSTA, 2012, p. 253) do

O Caderno Local do jornal O Liberal, de 26 de janeiro de 1984, deu destaque à matéria intitulada "Agromax responsável pelo Agente Laranja", na qual descreve as consequências da aplicação deste produto para realização do desmatamento em proveito das operações da UHE-Tucuruí. A matéria diz: "confirmado pelo Secretário Especial do Meio Ambiente do Ministério do Interior na época, Paulo Nogueira Neto, a utilização do Agente Laranja para o desmatamento no curso da linha de transmissão da Eletronorte próximo ao rio Moju, tendo ocasionado pelo menos a morte de quatro crianças além de animais. Arnaudo de Araújo, vice-presidente da Eletronorte, disse que a empresa não tinha conhecimento do uso dessa substância pela Agromax. Além disso, alegou que 'nunca foi pensamento da empresa desmatar a área a ser inundada pela barragem da hidrelétrica de Tucuruí, a não ser um perímetro de 10 quilômetros ao redor da Usina, que está sendo desmatado através de tratores". Uma empresa subcontratada pelo Consórcio ENGEVIC/Cetenco (contratado pela ELETRONORTE em 1984) para a manutenção da linha de transmissão da ELETRONORTE livre de vegetação lenhosa, acusada de usar Tordon-101 BR - principal herbicida utilizado na operação (com níveis mais baixos de contaminação de dioxina que o Tordon utilizado no Vietnã), Tordon-155 e BANVEL-450 (FEARNSIDE, 2015).

6 Costa (2012) utiliza estes conceitos para pensar as relações de produção rural na Amazônia paraense, no entanto, embora não tratemos de produtores rurais quando nos referimos 
ambiente, a escolha na região de influência de Tucuruí foi pela segunda, principalmente para que se continue a efetuar transformações tensas no ambiente ao "fornecer energia subsidiada para usinas multinacionais em Barcarena [...] e São Luís” (FEARNSIDE, 2015, p. 47).

\section{Consequência:}

- Aquelas água que foi pro fundo, as terras que foi pro fundo, tudo... (ÚRSULA).

Tudo? Beira, centro, terra livre, vida livre, riqueza, casa. Hoje foi para o fundo, naquela época, o ambiente que conferia plasticidade à morfologia social das pessoas deslocadas compulsoriamente. A articulação entre centro e beira (três tipos de beira: dos rios, do ramal de ligação da região de Tucuruí com a Transamazônica, e a beira da Estrada de Ferro Tocantins; a última, apenas beira), permitia ter roça no centro - distante das beiras, lugar, também, dos castanhais e da terra livre sem que se tivesse, necessariamente, terras; permitia morada na rua (lugares com equipamentos públicos, como escolas, postos de saúde etc.) ou em vilas (sem estes equipamentos); além de comércio e contato (nas beiras) (MAGALHÃES, 1996). A vida ocorria entre as beiras e o centro:

- O Moju, o Moju en digo que nem é beira [...]. Só tem a estrada. Eu fico olhando e imaginando: que adianta tá na beira? Acabou-se o centro... (MARILDA, Apud MAGALHÃES, 1996, p. 744).

Os lugares que foram para o fundo duram na memória durante um conflito que permanece e os atualiza, e que, como conflito, reflete e supõe haver mais de um interesse em relação ao ambiente e, consequentemente, sobre como seria saber viver nele. Uma expressão deste conflito resulta no reconhecimento de atingidos com "direito" - naquele contexto - ao reassentamento involuntário, que flutuou entre a estimativa de 15.000, anterior ao enchimento do lago, até 32.871 pessoas no início dos anos 1990 (FEARNSIDE, 2015). Esta discrepância acerca de quantas pessoas seriam deslocadas compulsoriamente remete, também, ao reconhecimento deste direito pela confirmação da propriedade através do título de terra (MAGALHÃES, 2007). Esta exigência modificou a forma de confirmação da relação com o ambiente, atrelando-a ao documento reconhecido pelos outros dos camponeses da região (chamados "compradores de direitos") em detrimento do critério do uso; significando, com isso, o tempo da terra livre no passado.

Há, na memória local, um desdobramento do conceito tempo da terra livre que o lança em níveis interpretativos distintos na medida em que se distancia,

à ELETRONORTE, percebe-se que o mesmo paradigma de dominação do ambiente que atravessa a perspectiva agropecuária está presente na elaboração de (grandes) obras com viés de desenvolvimentismo pela industrialização, esta, que por sua vez, se repete nas atividades rurais como sinal de progresso. 
no tempo cronológico, do evento que expande nas duas direções do presente a narrativa sobre o deslocamento compulsório. Aparece em princípio como tempo da terra devoluta (MAGALHÃES, 1996), no qual uma referência ao critério de classificação do Estado nomeia uma vivência; sendo elevado, posteriormente, ao nome de tempo da terra livre (MAGALHÃES, 2007), em que a experiência da terra devoluta nomeia a vivência da relação com o ambiente, adjetivado, por sua vez, em função dela; o tempo da terra livre torna-se tempo da vida livre (MERCÊS, 2017), nome no qual a significação da vivência do tempo da terra livre é elevado à interpretação da vida de quem interpreta o tempo da terra livre.

A elaboração destes níveis de interpretação da relação com o ambiente não culmina na exclusão do conceito cunhado em giro interpretativo anterior pelo mais recente nesta cronologia, mas sugere uma raiz comum em crescimento sem apagar os traços da trajetória que os formam; por mais que, enfim, este tempo não tenha "existido":

Os colonos não se referem ao "tempo da terra devoluta" como um mesmo tempo cronológico e objetivo. O "tempo da terra devoluta" é, sobretudo, uma construção social que parece ter como fundamento uma situação objetiva de terras potencialmente disponíveis, uma vez que pertencem ao Estado, aliada a uma representação sobre as "terras livres" que existiriam na Amazônia. Logo, o "passado" que é evocado pelos colonos individualmente, para falar sobre a terra devoluta, não contém uma mesma realidade factual, nem uma mesma data específica. Observa-se, ao contrário, que é em função do momento da chegada na região que se atribui uma data ao "tempo da terra devoluta" (MAGALHÃES, 1996, p. 728).

Desdobrar a compreensão de si no mundo, este é o fenômeno que anima a memória no Novo Breu como temporalidade comparável com a nomeada Breu $V$ elho. O evento ocorre, neste caso imposto, e altera a compreensão do tempo, rompe a duração cotidiana e desconecta a vivência pós-evento, compreendida como anterior ao presente que matiza um futuro possível que se abre com ele . $^{7}$ Esta ruptura aparece na narrativa das pessoas deslocadas compulsoriamente com as quais estudamos: por meio da memória nomeiam um passado que conformava

Dastur (2000) trabalha com uma compreensão do evento enquanto ocorrência dissonante da expectativa comum, ocorrência esperada com esperança que acontece como surpresa, que, nas palavras da autora: "introduces [...] between past and future and so allows the appearance of difference parts of time as dis-located. The event pro-duces, in the literal meaning of the word, the difference of past and future and exhibits this difference through its sudden happening" (DASTUR, 2000, p. 182). 
todo um complexo de possibilidades plausíveis e sugeria significação às vivências anteriores ao presente que evocava os êxtases daquela temporalidade. Não obstante, a ocorrência do evento muda a vida, altera a expectativa - pois o futuro já não é o mesmo - e a lembrança, que hoje referencia algo ausente, visto que o Breu Velho precisa não estar para, assim, ser simbólico ${ }^{8}$.

Em outras palavras, o evento "does not happen in a world-it is, on the contrary, as if a new world opens up through its happening" (DASTUR, 2000, p. 182). Com a abertura de um novo mundo pelo acontecimento do evento se instaura a sensação de necessidade de esforço para engajamento na temporalidade que se ergue com a vivência do deslocamento compulsório, pois, se "não há sujeito sem mundo" (NUNES, 2004, p. 15), como consequência de que "ser-nomundo, já na sua cunhagem, [...] pretende referir-se a um fenômeno de unidade" (HEIDEGGER, 2013, p. 98), é por ser coisa própria da vida enraizar-se e crescer no ambiente mundanizado (INGOLD, 2015).

\section{DAS TEMPORALIDADES}

Breu Branco é habitado, também, por deslocados compulsoriamente em função da implantação da UHE-Tucuruí. Estas pessoas chamam o lugar de "Novo Breu" em comparação com o "Breu velho", que hoje está no fundo do lago. Lá o termo melhoria de vida marca as expectativas acerca da implantação da UHE-Tucuruí, ocorrida entre os anos 1975, quando começam os estudos para a utilização da área para este fim, e 1984, quando se completa a primeira fase da obra, desencadeando o deslocamento compulsório de aproximadamente três mil famílias (MAGALHÃES, 2007). A melhoria de vida se insinua como promessa quando enunciada por representantes da ELETRONORTE aos camponeses dos lugares que foram para o fundo, uma situação que já perseguiam e que, em muitos casos, motivou o estar das pessoas que decidiram ficar nas áreas atingidas pelo lago.

Os camponeses atingidos em Breu Velho, reassentados no município de Breu Branco, bem como os nas demais localidades inundadas, com os quais

\footnotetext{
Como condição para significação, Eco (2012) compreende a necessidade da referência entre "entidades ausentes e entidades presentes" (ECO, 2012, p. 6) intersubjetivamente elaborada (o autor chama "sistema de significação") a ponto de pactuar que algo "materialmente presente à presença do destinatário está para qualquer outra coisa” (ECO, 2012, p. 6). Nesse sentido, a ausência do Breu Velho sugere, no Novo Breu, a significação da vida pela representação da temporalidade anterior ao evento, que, ao nomear uma sensação compartilhada de ausência algo, presentifica em reaparição a coisa ausente. O "estar-aí de um ausente ou de um desaparecido” (DERRIDA, 1994, p. 21) que já não responde pelo que era, a memória anima o Breu Velho como um espectro que reaparece, numa "repetição e singularidade" (DERRIDA, 1994, p. 26) que assombra o Novo Breu e lhe exige resposta pelo excesso de existir.
} 
não tivemos contato para esta pesquisa, estabeleciam etapas racionalizadas para justificarem a mudança de um lugar para outro, visto que eram migrantes voluntários ou atingidos por outras formas de expansão da fronteira do capital. As etapas consistiam em passear (aventurar)-agradar-dedicar. Passear ou se aventurar designa a iniciativa de sair de onde se estava para buscar a melhoria de vida em outro lugar; agradar seria a etapa subsequente, que confirmaria a melhoria de vida; dedicar seria a etapa de fixação e trabalho (cultivo, extrativismo etc.) no novo lugar escolhido (MAGALHÃES, 1996). No entanto, se o lugar de destino não agradava, o camponês não se dedicava e, portanto, voltava para onde havia saído.

Toda significação sugerida para Breu Branco corresponde a uma comparação com o Breu Velho ${ }^{9}$. Alçado à condição de município pela Lei Estadual no 5.703, de 13 de dezembro de 1991 (PARÁ, 1991), Breu Branco foi tanto uma conquista das demandas das pessoas da cidade, que realizaram esforço na coleta de assinaturas para a emancipação do Breu em relação a 'Tucuruí; quanto uma afronta do futuro candidato a prefeito nas eleições que aconteceriam no que era para ser o Novo Breu para os habitantes da cidade, originários do deslocamento compulsório da região:

Quando ele chegou com a documentação, “vamo' ler aí pra nós”... “Breu Branco". Ele deu uma cacetada em todo mundo, nós "tava" esperando Novo Breul, não era? A gente tinha saído do Breu velho e, por causa disso, aqui surgiu o Novo Breu (MAURÍCIO BABILÔNIA).

Violenta e surpreendente como a descoberta do nome do novo lugar foi também a ruptura que efetivou o deslocamento compulsório; não houve tempo para elaboração sistematizada por parte dos atingidos sobre o que estava acontecendo com eles. O evento não é elaborado simbolicamente em Breu Branco, não é nomeado e não tem paralelo em outras vivências destas pessoas, ele apenas marca uma sensação de diferença na vida delas. É pela ocorrência do evento que findou o tempo da terra livre, em que qualquer um que chegasse poderia escolher onde morar, respeitando o direito semelhante que os outros tinham e o trabalho de cada um sobre o lugar escolhido para ser casa (MAGALHÃES, 2007).

Avisaram nada. Toda área que foi desapropriado aonde foi inundado, não tem esse negócio de avisar a gente. Avisaram que ia ser feito a barragem e ia ser inundado tudo lá e a gente tinha que mudar pra outro lugar onde não fosse ser inundado (JOSÉ ARCÁDIO).

\footnotetext{
Tanto que os adjetivos "novo" e "velho" complementam o nome do lugar com maior frequência que a utilização do nome oficial da cidade.
} 
Me disseram "você aqui não pode ter atividade nenhuma mais", [...] quem plantava roça não pode mais plantar, quem fazia isso não pode mais fazer... Eu plantava roça, era agricultor (MAURÍCIO BABILÔNIA).

A categoria elaborada pelos deslocados compulsoriamentepara descreverem as formas de viver o mundo antes da barragem, nomeando-o tempo da terra devoluta e tempo da terra livre, durante os anos posteriores ao evento foi articulada em um sentido mais abrangente para compreenderem aquela temporalidade no período em que situamos nossa pesquisa de campo. Entre 2016 e 2017, o tempo da terra livre era secundarizado em relação ao tempo da vida livre; sendo, a partir dali, o tempo da vida livre uma característica da temporalidade anterior na qual a constituição de si com o ambiente era outra e a interpretação da trajetória tecnológica ${ }^{10}$ que fora efetivada é recolocada em outro nível hermenêutico para compreender a ontologia que dinamizava as práticas sociais.

A vida livre era uma vida muito tranquila na floresta, com oxigênio puro, porque viver dentro da mata é muito ótimo para quem está acostumado. Quem não está não ia se dar muito não (MAURÍCIO BABILÔNIA).

Era mais farto, naquele tempo era. Nossa! Lá era mais... Era carne de caça, porque quase não tinha carne de gado, não é? E nós andava de trem (ÚRSULA).

Era tudo calmo, eu morei esses vinte e tantos anos, vinte e quatro, trinta... Tu tinha o peixe, tu tinha o açaí, tu tinha bacaba, tu tinha o cupu, tu tinha castanha, tu tinha tudo. Tu ia no rio lá, a gente não chegava no mercado pra comprar peixe não, os homens iam pegar peixe e, "vizinha, pega aqui peixe pra você (REBECA).

Todas as pessoas ali que foram vítimas do deslocamento compulsório tentaram, de uma forma ou de outra, reconstruir suas vidas onde passaram a estar depois do evento. Maurício Babilônia tentou novamente ser agricultor, mas as terras que recebeu em compensação pela ELETRONORTE não lhe permitiam insistir nessa intenção. Úrsula trouxe do Breu Velho a arara azul com a qual tinha se afeiçoado, além de uma macaca; que, de velhas, morreram em Breu Branco; e Rebeca lamenta a obrigatoriedade em sair:

10 Francisco Costa (2012) compreende a trajetória tecnológica como "um padrão usual de atividades que resolvem, com base em um paradigma tecnológico, os problemas produtivos e reprodutivos que confrontam os processos decisórios de agentes concretos em contextos específicos, nas dimensões econômica, institucional e social"' (COSTA, 2012, p. 248). A própria definição de trajetória tecnológica do autor insinua a possibilidade de situar sua dinâmica em diferentes níveis hermenêuticos, abrangendo desde estas soluções práticas (trajetórias tecnológicas) até os modelos de relação com a natureza que legitimam determinadas práticas e seu desdobramento em favor de uma ontologia. 
Ainda vieram para cá. Era solta ela, ela [a arara], a macaca, andavam tudo por aî" (ÚRSULA).

Se não tivesse esse medo de barragem a gente não saia não, de jeito nenhum. A gente vivia bem (REBECA).

Como não puderam escolher, tentam reconstruir o que lhe falta no novo Breu. No último campo que fizemos, até a redação destas páginas, Rebeca nos convidou para conhecer o terceiro andar de sua casa, depois de várias reformas no lugar recebido como indenização pela ELETRONORTE, que estava irreconhecível quando comparada com a planta da empresa, descrita, por meio do "termo de acordo amigável"11, da seguinte forma:

CLÁUSULA TERCEIRA - Que, em cumprimento desse programa de reassentamento populacional, a CEDENTE dotará o BENEFICIÁRIO de um lote urbano com dimensões de 12,00 metros de frente por 30,00 metros de fundos, totalizando uma área total de 360,00 metros quadrados, representado pela QUADRA X, LOTE X, nele estando edificadas uma casa PADRÃO URBANO, com as seguintes características: Pré-fabricada, em madeira serrada imunizada, piso de cimento, paredes internas e externas em madeira serrada, pintada a óleo, dependência sanitária em alvenaria, contendo seis repartições internas, sendo (03) três quartos, 01 (uma) cozinha, 01 (uma sala), 01 (um) banheiro e uma área de serviço, dotada de instalações hidráulicas e elétricas, cobertura de telha fibrocimento e área total de 47,18 metros quadrados ${ }^{12}$.

No térreo da casa de Rebeca funciona o negócio da família. A principal fonte de renda é uma fábrica de pré-moldados, que apareceu como opção depois que a primeira tentativa de reconstruir a vida no Novo Breu - uma "vendinha" - não deu certo por terem sido furtados algumas vezes. No segundo pavimento funciona a casa. A apresentação do terceiro pavimento foi precedida de uma breve descrição enquanto subíamos os degraus de uma escada estreita emoldurada por paredes verde dos dois lados com um corrimão de alumínio para a mão direita: "aqui é minha floresta".

11 Este "Acordo" integra o arquivo dos deslocados compulsoriamente sobre o evento que temos em foco. Guardado em uma pasta de papelão e elástico, reúne documentos relativos ao deslocamento compulsório produzidos em períodos distintos, dispostos na mesma ordem independente da pessoa a quem pertença a pasta. No entanto a ordenação dos documentos não segue a cronologia de sua ocorrência, o que pretendemos como tema de discussão em outro artigo.

12 Fonte: arquivo dos deslocados compulsoriamente; trabalho de campo. 
Figura 1 - Floresta de Rebeca no Novo Breu (1ª)

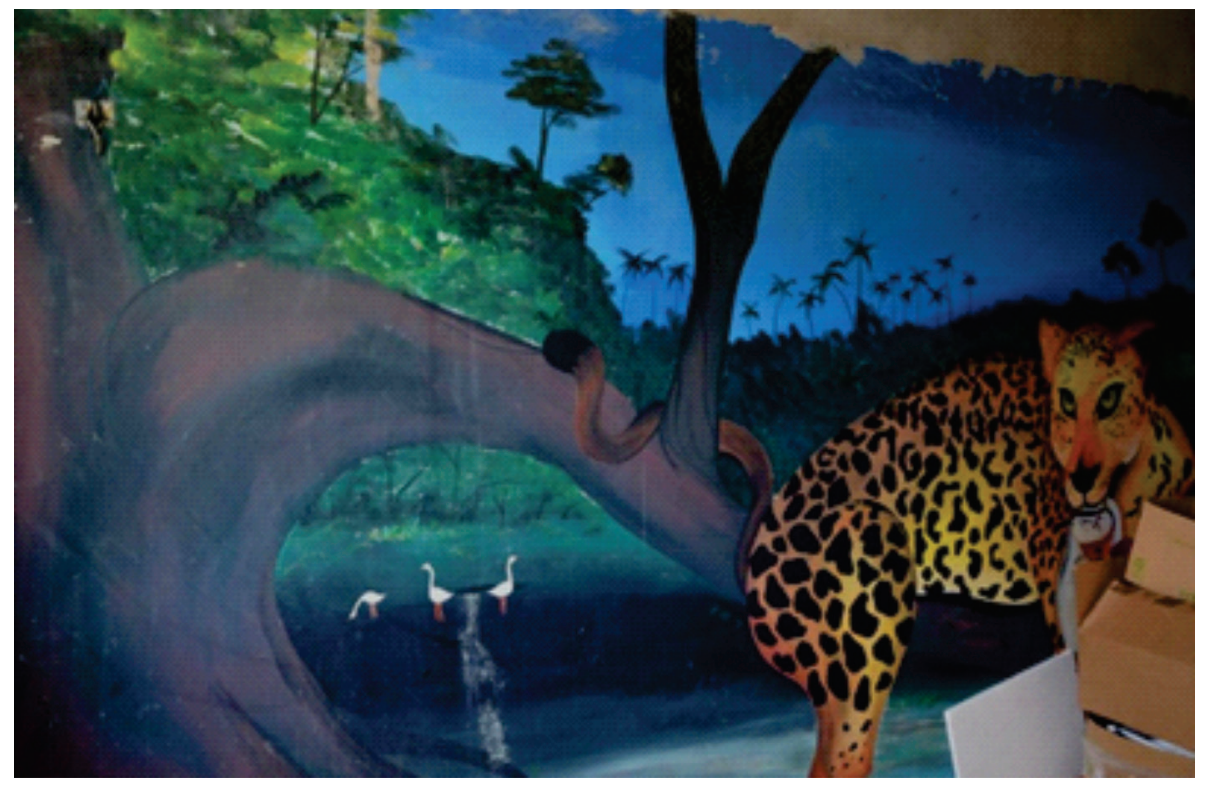

Fonte: Trabalho de campo. Fotografia: Vitória Mendes $^{13}$.

Figura 2 - Floresta de Rebeca no Novo Breu $\left(2^{a}\right)$

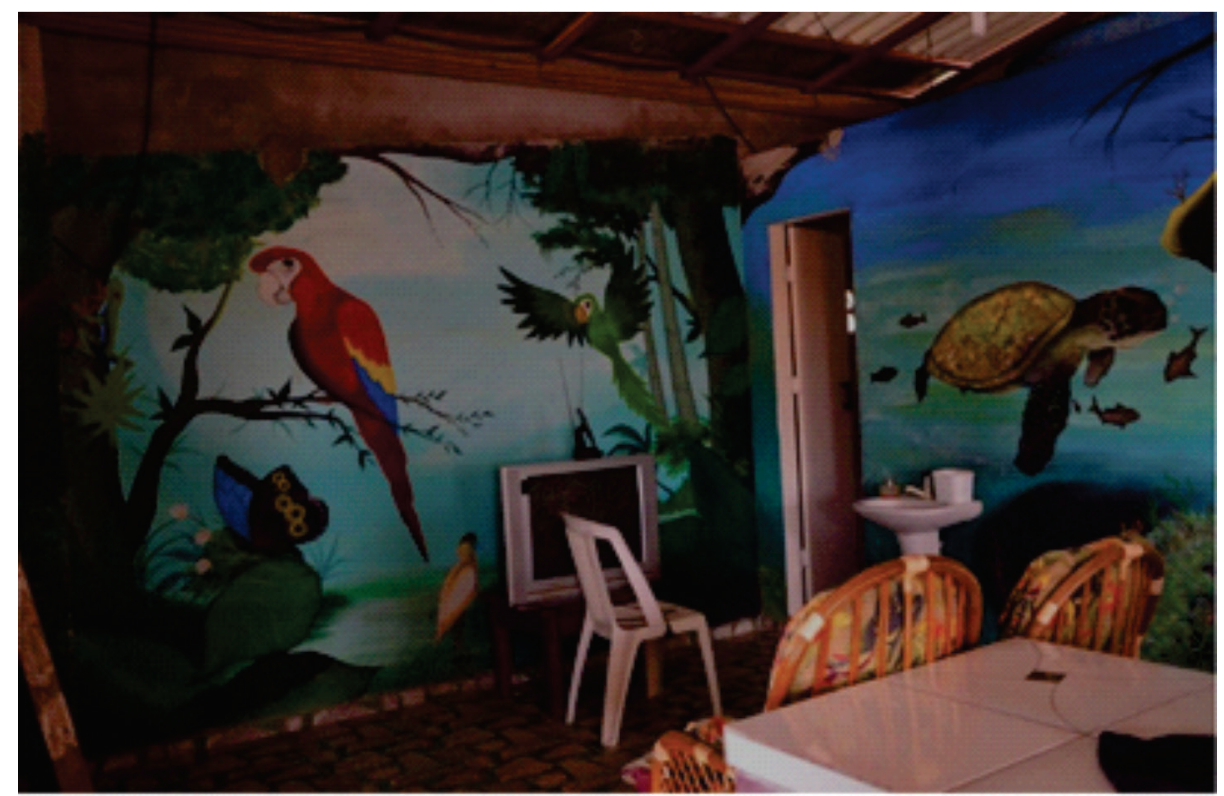

Fonte: Trabalho de campo. Fotografia: Vitória Mendes

$\overline{13}$ Pesquisadora vinculada ao mesmo projeto de pesquisa que o autor, responsável pelas fotografias.

Novos Cadernos NAEA • v. 22 n. $2 \cdot$ p. 225-246 • maio-ago 2019 
Como Rebeca, Úrsula também possui seus arquivos, os suportes técnicos para a memória em favor do seu dever de não esquecer (RICCEUR, 2007). Ela tem um baú pequeno, de madeira, que, sentada numa cadeira depois de retirá-lo de um móvel na sala de sua casa, colocou sobre as pernas para contar acerca do Breu velho. Vimos o baú apenas na primeira vez em que estivemos em Breu Branco. Nesta ocasião ela retirava dele fotografias antigas no meio das quais haviam outros objetos que não pudemos identificar enquanto ela mostrava as fotos e descrevia as situações nas quais tinham ocorrido. Além das fotografias, Úrsula mantém em sua casa em Breu Branco algumas telhas oriundas da temporalidade anterior, trazidas da sua "despedida" do Breu velho:

Nós fomos pra lá, passamos dois dias lá. Agora só quem já conhecia mesmo o lugar que a pessoa morava que tava que a gente viu. A gente viu o colégio, que tava caído, já tava derrubado o colégio, não é? Que eles derrubavam. Na hora que saia o povo tudinho se fosse de alvenaria eles derrubavam, era a máquina da Eletronorte, eles derrubavam, né? Não ficava nada, eles derrubava. Aí tava o colégio, passamos no colégio, tinha muita telha ainda. Aí eu ainda tenho até umas telha aí que a gente trouxe que é da estrada de ferro, mas tá por aí misturado com essas outras aí. Ainda tinha o poço que nós pegava água, a igreja, mas tava tudo derrubado, sabe? Aí quando nós fomos lá no Breu velho, que nós fomos lá e passamos dois dias lá. Nós fomos de "avoadeira", fomos de "avoadeira" e passamos dois dias lá, mas aquilo lá foi uma tristeza. Porque a gente chega lá, um lugar tão bonito... porque lá, lá o Breu.... Era assim, plano e era só areia mesmo, areia mesmo lá, sabe? A beira do rio era perto. A praia, a praia muito grande lá. Era muito bonito lá.

[...]

Então quando nós fomos lá passar esses dois dias que nós passamos lá, nós passamos lá, foi assim... Uma tristeza para nós. Foi eu, foi os dois meninos, o meu neto que era pequeno ainda. Eles eram pequeno ainda, sabe? Essa aí, essa daí foi também [apontando para a neta], mas eles eram tudo pequeno ainda, e nós fomos. Mas nós passamos um medo medonho na "avoadeira" que nós fomos, sabe? Aí eu levei eles dois.

Quando nós chegamos lá... Foi mais gente na nossa frente, foi muita gente na nossa frente, sabe? Foi pra lá, chegaram lá e fizeram uma serenata, passamos a noite lá, mas sem casa e sem nada, amarramos as redes nos paus lá e ficamos dois dias lá.

$[\ldots]$

Chegando lá foi uma tristeza, só as coisas tudo caído, sabe? Fui no lugar da minha casa ainda, que era o lugar da minha casa que eu morava, sabe? Fui no lugar da minha casa e não tinha mais nada, só tinha uns paus, uns tocos e a gente só conhecia porque era pra conhecer mesmo, sabe? Aí de lá nós viemos e tinha o aeroporto lá... a pista do avião; aí tinha a igreja, tinha o colégio, tinha o poço de pegar água, o poço tava do mesmo jeito e muitas 
casas a gente ainda via no jeitinho, né? Porque eles derrubavam na hora que a pessoa saia da casa, eles derrubavam com medo acho que da pessoa voltar de novo lá pra dentro da casa, aí eles derrubavam ${ }^{14}$.

Outras pessoas que vivenciaram o deslocamento compulsório ali também mantêm seus suportes para memória, além, também, do arquivo comum a todos: os documentos da contenda com a ELETRONORTE. Todos guardam fotografias - as de José Arcádio emolduram a parede da sala de sua casa, e retratam o time de futebol do Breu velho -; alguns, ferramentas das atividades da vida anterior, como o material utilizado para fazer canoa de um dos senhores que vive hoje em Breu Branco. Segundo o que contam e o que ele próprio diz, era o responsável por fazer os barcos que utilizavam no Breu Velho para pescar. Todos sabem e não querem esquecer o porquê estão ali e como foi para estarem:

Então eu digo que era assim: era um paraíso lá, que tinha tudo, né? Mas aí, como "as coisa" é desse jeito, por causa das barragens, dessas coisas, foi se acabando tudo, né? E no fim a gente vai ficando assim (REBECA).

As condições em que o Novo Breu foi entregue aos deslocados compulsoriamente colaboram para dar o tom melancólico à temporalidade posterior a este evento. $\mathrm{O}$ futuro anterior (tomando o evento como momento de referência) prometia - seja pelos números que creditam à dívida da ELETRONORTE pelo processo de deslocamento compulsório no entendimento dos atingidos ${ }^{15}$ e pela dinâmica econômica que ele instauraria (comércio, escolas, trabalho: as vilas virariam rua), abrindo a possibilidade de se agradarem do novo lugar - como consequência a melhoria de vida.

Quando a melhoria de vida não vem, e, pelo contrário, sente-se o inverso disso, a violência do deslocamento compulsório se estende à impossibilidade de volta $^{16}$ e ressoa na duração da temporalidade que ele instaura. É ao sentido deste tipo de acontecimento que Dastur (2000) dirigiu o questionamento que guiou sua formulação conceitual do evento: "How can we account for these moments of crisis, of living death, of trauma, when the whole range of possibilities of

14 Editamos a entrevista, suprimindo os nomes próprios dos familiares pelo mesmo motivo que utilizo pseudônimos para nossos interlocutores.

15 Em junho/julho de 2016, Rebeca falava acerca das reuniões referentes ao processo que envolvia o Programa Social para os Expropriados de Tucuruí (PROSET), que "agora tão dizendo que iam indenizar o restante, dizem que era $\mathrm{R} \$ 40.000,00$; semana passada a gente foi numa reunião e já não é mais $R \$ 40.000,00$, é só $R \$ 5.000,00$. Aí eles vão só enrolando a gente, sabe? Só enrolando, enrolando... Nunca terminaram de pagar".

16 Como se pode perceber da fala de José Arcádio ao explicar o motivo de não ter ido com Úrsula e demais deslocados compulsoriamente ao Breu velho no que chamamos aqui de "despedida": "eu não fui porque olhar pro passado é sofrer duas vez". 
a human being becomes unable to integrate the discordance of the event and collapses completely" (DASTUR, 2000, p. 185)? A resposta tem base na nossa confiança no mundo: "ordinary experience presupposes an originary faith in the stability of the world and the presumption that experience will always have the same 'style"' (DASTRUR, 2000, p. 185).

Foi difícil, Até hoje! Até hoje... Eu tô com trinta e um anos que nós mora aqui, mas sei lá, eu sinto falta do Breu de lá. Sinto muita falta porque a gente tinha liberdade, lá a gente pescava, a gente tirava castanha, a gente caçava, a gente tinha tudo (ÚRSULA).

O evento criou barreiras para a reorganização social do tipo de vida que estas pessoas praticavam no Breu velho, não que tenha impedido a vida, mas que exigiu uma atividade criativa sem ensaio prévio. Agradar-se do lugar era o teste, a etapa que confirmaria a dedicação, no entanto, mesmo com a possibilidade de se agradar no novo Breu aberta pelo deslocamento compulsório, sua imposição não deixava alternativa de retorno caso o agrado não fosse confirmado. Assim, tiveram de refazer as histórias das coisas com que se deparavam, não sendo elas inovações em um mundo dinâmico, mas a marca de ausência de uma possibilidade de narratividade de ser-no-mundo:

Tu chegava, "vou fazer uma casa", e juntava todo mundo pra fazer aquela casa, quando outro ia fazer juntava todo mundo e ia fazer a casa, era assim. Aqui não, se tiver dinheiro tu faz, se não tiver... Né? Era muito bom lá, foi muito bom (REBECA).

Era um lugar pequeno, quando doía a barriga lá, no fim da rua todo mundo já sabe e vai visitar, tem aquele amor, aquela dedicação. Hoje aqui no Breu, nós que somos aqui do Breu... Morre gente aqui, matam, e depois procura, "e fulano?", dizem "ih, faz é tempo que morreu, faz é dias que morreu”; não é assim? Pois é, é diferente, não é? Naquele tempo o cabra chegava com fome na casa do outro, enchia o prato de farinha e chamava ele pra comer. Hoje a maior parte do povo não tem mais esse amor uns pelos outros, você concorda comigo? Né não? Só quer saber de dinheiro (JOSÉ ARCÁDIO).

A existência de um estar que permitiu a ligação da terra livre-vida livre, em que o ambiente era uma abertura às necessidades e a "propriedade" funcionava mais como uma sensação de meios úteis à satisfação de necessidades próximas, foi substituída por um discurso de ordem simbólica, baseada na escrita e no direito; instituições alienígenas para uma população majoritariamente analfabeta e alheia, até então, ao Estado enquanto instância reguladora das relações cotidianas. A escolha de onde habitar e como fazê-lo foi reduzida pelas determinações 
contratuais estipuladas nas cláusulas sete e oito do "termo de acordo amigável" com a ELETRONORTE:

CLÁUSULA SÉTIMA - Assume outrossim o BENEFICIÁRIO, neste ato, as seguintes obrigações:

a) - Residir na casa e preserva-la contra invasões;

b) - Não alienar, transferir, alugar ou ceder a casa à qualquer título sem expressa anuência da CEDENTE;

c) - Acatar as normas de postura urbana municipal, bem como todas aquelas inerentes à estruturação e constituição do Loteamento;

d) - Zelar pela integridade física e conservação dos prédios e equipamentos comunitários implantados pela CEDENTE, até que sejam transferidas para as administrações das Prefeituras Municipais que deverão ficar encarregadas pelo funcionamento e manutenção dos mesmos.

A Transgressão de alguma das condições acima estabelecidas dará direito à CEDENTE de tornar plenamente rescindido o presente Contrato, revertendo a o lote e a casa nele edificada ao seu patrimônio.

CLÁUSULA OITAVA - Que, finalmente, se compromete a CEDENTE a outorgar a respectiva Escritura Pública de D'ação em pagamento investindo o BENEFICIÁRIO na propriedade do lote e da casa nele edificada sem ônus de qualquer natureza ${ }^{17}$.

\section{DO EXCESSO}

A duração do sofrimento social desencadeado pelo evento está associada à noção de ruptura. No entanto, sugerimos que há uma ruptura drástica, que justificaria, em partes, a dificuldade de se reestabelecerem os deslocados compulsoriamente, como partícipes de um ambiente familiar, no qual a sensação de habitar pudesse ser reconstruída mesmo que em bases diferentes daquelas do Breu Velho. Não há dúvidas de que vivem no Novo Breu, de que desenvolveram habilidades comerciais, narrativas ${ }^{18}$, políticas $^{19}$, que ampliaram horizonte de

${ }_{17}$ Fonte: arquivo dos deslocados compulsoriamente; trabalho de campo (2016).

18 Sônia Magalhães (2007) descreve a participação dos deslocados compulsoriamente em encontros promovidos em função do evento, no qual os atingidos participavam narrando suas histórias em relação ao ocorrido: como referência temos o Encontro Tucuruí e o Encontro de 2003 (MAGALHÃES, 2007). O primeiro foi realizado em 30 de outubro e 01 de novembro de 1984 "num conjunto de manifestações públicas iniciadas em 1982 [...] com o expresso propósito de chamar a atenção da sociedade de Tucuruí e de Belém e de seguimentos da sociedade nacional não só para a questão do deslocamento compulsório, mas também para a questão indígena e para o autoritarismo que caracterizava toda a atuação da empresa, especialmente numa conjuntura de ditadura militar" (MAGALHÃES, 2007, p. 217). O segundo, realizado entre 10 e 12 de abril de 2003 "foi promovido pela ELETRONORTE, o Museu Paraense Emílio Goeldi e o Centro Universitário do Pará (CESUPA)" (MAGALHÃES, 2007, p. 220) no qual as falas rituais não foram permitidas pelos organizadores, embora tentada pelos deslocados compulsoriamente que estiveram presentes.

19 José Arcádio foi vice-prefeito e vereador em Breu Branco em razão, segundo ele, de sua luta para tornar o lugar mais aprazível aos seus moradores, tendo sido responsável tanto pela escolha 
mundo. No entanto, também não há dúvidas de que o Breu Velho paira como um lugar mítico sobre o Novo Breu, apontando o que falta na temporalidade do hoje.

Falta ao Novo Breu ser mundo e completar a unidade que o "ser-nomundo" da fenomenologia heideggeriana atribui à vida humana:

"em" deriva-se de innan-, morar, habitar, deter-se; " $n a$ " significa: estou acostumado a, habituado a, familiarizado com, cultivo alguma coisa; possui o significado de colo, no sentido de habito e diligo. O ente, ao qual pertence o ser-em, neste sentido, é o ente que sempre eu mesmo sou. A expressão "sou" conecta-se a "junto"; "eu sou” diz, por sua vez: eu moro, detenho-me junto... ao mundo, como alguma coisa que, deste ou daquele modo, me é familiar (HEIDEGGER, 2013, p. 100, grifos do autor).

Um resultado que o deslocamento compulsório não poderia gerar; que, na verdade, impediria de acontecer sem exigir um tipo de esforço e dedicação que escapam às vontades, exigindo comprometimento da imprevisibilidade do destino, talvez na forma de um novo evento. Explica-se: Geertz (2012) descreve a noção de pessoa na ontologia ocidental:

Um universo cognitivo e motivacional delimitado, único, e mais ou menos integrado, um centro dinâmico de percepção, emoção, juízos e ações, organizado em uma unidade distinta e localizado em uma situação de contraste com relação a outras unidades semelhantes, e com seu ambiente social e natural específico (GEERTZ, 2012, p. 63-64).

A esta compreensão, Ingold (2015) chama "lógica da inversão", que faz com que "seres originalmente abertos para o mundo" sejam "fechados em si mesmos, selados por uma fronteira externa ou casca que protege a sua constituição interna do tráfego de interações com o meio envolvente” (INGOLD, 2015, p. 117): uma consequência do desenvolvimento da cultura ocidental, a partir de uma razão dualista e instrumental, com algumas consequências convenientes aos imperialismos, que dela também resultam. Por meio desta lógica, "o campo de envolvimento no mundo, de uma coisa ou pessoa, é convertido em um esquema interior cuja aparência e comportamento manifestos são apenas expressões exteriores" (INGOLD, 2015, p. 117).

Como fato social (DURKHEIM, 2007), baseamos nossas ações nesta impressão do que somos. Defendemos que a inversão, porque desloca a vida em favor de uma explicação que a ignora (esta é a tese de Ingold (2015), é a causa do excesso. A razão do Estado, com seus instrumentos de efetivação, por

do lugar onde seriam reassentados os deslocados do Breu Velho como pela emancipação de Breu Branco em relação a Tucuruí. 
meio da política de reassentamento, provoca ofensas maiores que as indenizações possíveis e reclamadas ao incidir sobre o porvir das linhas de um habitar possível no quando de sua ocorrência.

Imageticamente a pessoa ocidental de Geertz (2012) seria:

Figura 3 - Inversão da pessoa na cultura ocidental

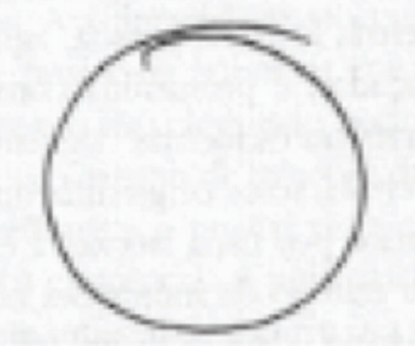

Fonte: Ingold (2015, p. 118)

A inversão, tema subjacente à subjetividade, esta que "acaba por instituir um universo paralelo ao mundo" (CASTRO, 2012, p. 170), no qual o sujeito existe "enquanto substrato aos acidentes do mundo" (CASTRO, 2012, p. 170), pode (e faz) conferir legitimidade à política de deslocamento compulsório das pessoas atingidas diante de discurso jurídico e mesmo frente ao discurso ético - como dissemos, a inversão é um fato social. Assim se torna possível, com base nesta representação, dissociar a subjetividade (a pessoa e as pessoas) do (que, como consequência, se torna um) "substrato inerte sobre o qual os seres vivos movemse como fichas em um tabuleiro ou atores em um palco" (INGOLD, 2015, p. 121), que seria o ambiente ou, de modo mais abrangente, o mundo do ser.

No entanto, em um plano não representado, mas sentido no devir em que ocorre a vivência, a legitimidade do deslocamento compulsório tende a não se conformar para quem foi atingido desta forma. Há cicatrizes do excesso: "isso nós não perdoa" (Maurício Babilônia). Isso: o excesso; o ato lesivo de "lesar uma pessoa" (Maurício Babilônia). Para Ricœur (2007) o excesso:

não se trata mais de um simples contrário que eu ainda compreenderia em oposição ao válido; são males que se inscrevem numa contradição mais radical que a do válido e do não-válido e suscitam uma demanda de justificação que o cumprimento do dever não satisfaria mais (RICCEUR, 2007, p. 470-471).

Excede a justificativa e a legitimidade provavelmente porque incide sobre o não representado, sobre o que não é simbolizado, naquilo que ocorre de forma 
fluida por meio de habilidades de um tipo de viver que dissolve as fronteiras entre percepção e ação nos fluxos sensoriais que escapam à "inteligência” (INGOLD, $2015)^{20}$. Incide sobre a familiaridade do agir no mundo em que as ações eram possíveis, pois que, desfeita a inversão, com o ser que vive o mundo não "existe interior ou exterior, e nenhum limite separa os dois domínios. [...], relação não é entre uma coisa e outra - o organismo 'aqui' e o ambiente 'lá'. É, antes, uma trilha ao longo da qual a vida é vivida" (INGOLD, 2015, p. 118, grifos do autor).

Figura 4 - A forma da vida

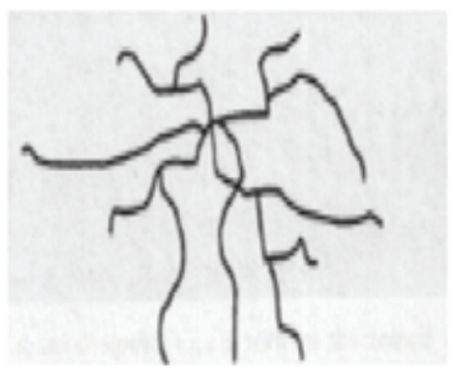

Fonte: Ingold (2015, p. 119)

As tentativas de justificação (que são muitas desde 1984) ${ }^{21}$, sem sucesso, repercutem, até hoje, sobre a dinâmica refletida da vida, sobre a "inteligência", objetivando solucionar o problema sugerindo comparação entre valores que podem ser, e no caso são, incomunicáveis entre as formas de se ser humano.

20 O autor alega "inteligência é uma coisa, agência é outra completamente diferente. É um erro grave confundir as duas coisas" (INGOLD, 2015, p. 151, grifo do autor). Afirma que "a essência da ação não reside na sua premeditação [...], mas no estreito acoplamento do movimento corporal e da percepção" (INGOLD, 2015, p. 151, grifo do autor) que permitem a maior parte da nossa vida (não se pensa "vou erguer o braço para levar o garfo à boca", ou "ajeitarei os dedos de tal forma para segurar a caneta de modo que possa manter firme os traços que pretendo escrever”; a não ser que se esteja aprendendo uma nova habilidade na qual a consciência interromperia as etapas da ação "naturalizada" pelo hábito).

21 Como exemplo, tomemos o caso do Programa Social para os Expropriados de Tucuruí (PROSET). O programa em questão tinha como objetivo mitigar o conflito entre os atingidos pela primeira fase da construção da UHE-Tucuruí e a ELETRONORTE, sendo ele a solução acordada entre ambos os grupos para as demandas dos deslocados compulsoriamente, que entre 2003 e 2004 ocuparam a vila permanente da empresa (destinada aos seus funcionários) para reivindicarem o cumprimento das promessas que a Eletronorte havia feito na ocasião do deslocamento compulsório. O acordo, firmado em 30 de novembro de 2004, previa a destinação de R \$ 39.900.000,00 para consolidação de bases produtivas viáveis socioeconomicamente aos atingidos por meio da criação de cooperativas agroindustriais em Novo Repartimento, Itupiranga, Nova Ipixuna, Breu Branco, Goianésia e Tucuruí. No entanto R \$ 16.853.978,90 não foram repassados pela Eletronorte aos deslocados compulsoriamente, sendo este o objeto de disputa até 11 de agosto de 2016, quando foi decidido pelo Ministério Público Federal (MPF) o pagamento por parte da Eletronorte aos deslocados compulsoriamente o valor de R\$ 12.123.314,60, distribuídos entre 2.343 famílias, que receberiam, cada uma, parcelado em três vezes, o valor total de 5.088 reais à receberem a partir de outubro daquele ano. 
Se na esfera simbólica a narrativa local afirma que a ELETRONORTE "nunca terminaram de pagar" (REBECA), é porque, talvez, estes valores refiram-se às linhas que permitiam uma forma de "geração de ser, em um mundo que não é preordenado, mas incipiente, sempre à beira do atual” (INGOLD, 2015, p. 117) pelas direções da vida que se expandem ao porvir possível que o crescimento delas, em determinado mundo, permite.

\section{CONSIDERAÇÕES FINAIS}

O evento rompe as linhas da vida antigamente, cinde a temporalidade e indica outras linhas possíveis pelo esforço e pelo destino, no entanto se articula à justificação no âmbito da linguagem - Ingold (2015, p. 157-178) interpreta as representações contraditórias da Terra, céu e chão em imagens produzidas por crianças analisadas por psicólogos, conclui que as contradições repousam, sobretudo, na duplicidade humana: “'humano’ é uma palavra que aponta para o dilema existencial de uma criatura que pode conhecer a si mesma e ao mundo de que é parte somente através da renúncia ao seu próprio estar nesse mundo"22 (INGOLD, 2015, p. 177) ${ }^{23}$. A "inteligência"24 abarca uma parte da vida, mas aparentemente não é suficiente para refazer os caminhos que a vivência traçara, fazendo durar o conflito que dura pelo excesso refletido no Breu Velho obsidiar ${ }^{25}$ o Novo Breu.

Assombrado pelo antigamente, o hoje traz a narrativa mnemônica do quase ausente, que espreita invisível esperando a oportunidade de reaparecer, o efeito de memória que a linguagem, na forma narrativa, representa: "um passado que

22 Embora o aparente dualismo na argumentação de Ingold (2015), o autor retorna aos dois termos que formam a humanidade reafirmando que apenas a compreensão da unidade, não como faces de uma mesma moeda, mas como processo no qual ora a vida privilegia o foco em um polo, ora noutro; e que somente a compreensão de continuidade entre estas formas humanas de vida, pois "o desenho molda o mundo em que vivemos, ao mesmo tempo em que molda nossa própria humanidade" (INGOLD, 2015, p. 178).

23 Outras palavras para dizer etnograficamente que o "privilégio ôntico que distingue [nossa existência] está em ela ser ontológica” (HEIDEGGER, 2013, p. 48).

24 Os processos de simbolização derivam do "modo como a matriz simbólica cifra o acontecimento em questão” (FINK, 1998, p. 38), sendo possível a existência de excesso sobre a cifragem. Esse excesso não-simbolizado aparece como real e insiste em retomar nas derivações dos eventos que a experiência simbólica não conteve em uma forma socialmente reconhecida no ambiente que deu base ao acontecimento. Assim, o real escapa ao simbólico, dando vasão aos modos de estar vivo que Ingold (2015) sugere.

25 "Invisível entre seus aparecimentos" (DERRIDA, 1994, p. 22) que vê sem ser visto à espreita de acontecer novamente, a memória do Bren Velho, que permanece "inefetivo, virtual e inconsistente" (DERRIDA, 1994, p. 26) até ser, novamente e a cada vez, reapresentado pela presentificação no Novo Breu e, assim, dar forma a uma saudade. 
nomeia um presente com o vigor-de-ter-sido [...] e um presente que nomeia um passado em função de um porvir" (CASTRO, 2010, p. 209) em razão de uma "produção de desejos de alteridade" (CASTRO, 2010, p. 211) fundamentados, sobretudo, na injustiça do excesso que inaugura o hoje. O testemunho do evento não é mais condição da narrativa, a memória do Breu Velho, insidiosa, é narrada pela segunda geração a partir dos deslocados compulsoriamente, e talvez pela terceira ${ }^{26}$, sem início... Restando-nos a dúvida se "as estirpes condenadas a cem anos de solidão não terão uma segunda chance sobre a terra”.

\section{REFERÊNCIAS}

CASTRO, Fábio. A Cidade Sebastiana: era da borracha, memória e melancolia numa capital da periferia da modernidade. Belém: Edições do autor, 2010.

CASTRO, Fábio. Arqueologia do sujeito moderno: por uma crítica não-metafísica da identidade. Rev. Humanitas, Fortaleza, v. 27, n. 1, p. 166-180, 2012.

CASTRO, Fábio. Sociedade dos arquivos: temporalidade e intersubjetividade na cultura contemporânea. Contracampo, Niterói, v. 35, n. 02, p. 183-199, ago. 2016. COSTA, Francisco. Mercado de terras e trajetórias tecnológicas na Amazônia. Economia e Sociedade, Campinas, v. 21, n. 2 (45), p. 245-273, 2012.

DASTUR, Françoise. Phenomenology of the event: waiting and surprise. Hypatia, v. 15, n. 4, p. 178-189, 2000.

DERRIDA, Jacques. Espectros de Marx: o estado da dívida, o trabalho do luto e a nova Internacional. Rio de Janeiro: Relume-Dumará, 1994.

DURKHEIM, Émile. As regras do método sociológico. São Paulo: Martins Fontes, 2007.

ECO, Umberto. Tratado geral de semiótica. São Paulo: Perspectiva, 2012.

FEARNSIDE, Philip. Hidrelétricas na Amazônia: impactos ambientais e sociais na tomada de decisões sobre grandes obras. Manaus: Editora do INPA, 2015.

FINK, Bruce. O sujeito lacaniano: entre a linguagem e o gozo. Rio de Janeiro: Jorge Zahar, 1998.

GEERTZ, Clifford. O saber local: novos ensaios em antropologia interpretativa. Petrópolis: Vozes, 2012.

26 História que ainda não podemos contar por falta de material. 
HEIDEGGER, Martin. Ser e tempo. Petrópolis: Vozes; Bragança Paulista: Editora Universitária São Francisco, 2013.

INGOLD, Tim. Estar vivo: ensaios sobre movimento, conhecimento e descrição. Petrópolis: Vozes, 2015.

MAGALHÃES, Sônia Maria. O desencantamento da beira: reflexões sobre a transferência compulsória provocada pela Usina Hidrelétrica de Tucuruí. In: MAGALHÃES, S. BRIT'TO, R. CASTRO, E. (Orgs.). Energia na Amazônia. Belém: MPEG: UFPA: UNAMAZ, 1996. v. 2, p. 697-746.

MAGALHÃES, Sônia Maria. Lamento e dor: uma análise sócio-antropológica do deslocamento compulsório provocado pela construção de barragens. Belém, 2007. Tese (Doutorado em Ciências Sociais) - Universidade Federal do Pará, Belém, Brasil; Universidade París 13, Paris, França, 2007.

MÁRQUEZ, Gabriel García. Cem anos de solidão. Rio de Janeiro: Record, 2014.

MERCÊS, Jorge. Memórias da promessa e do fim do mundo: experiência vivida do deslocamento compulsório em Tucuruí. Belém: PPGSA/UFPA, 2017.

NO rastro do agente laranja. O Liberal, Belém, 04 jan. 1984. Caderno Local.

NUNES, Benedito. Heidegger \& ser e tempo. Rio de Janeiro: Jorge Zahar. 2004.

NUNES, Benedito. O tempo na narrativa. São Paulo: Edições Loyola, 2013.

PARÁ. Assembleia Legislativa do Estado do Pará. Lei N. 5.703, de 13 de dezembro de 1991. Cria o Município de Breu Branco e dá outras providências. Belém: Assembleia Legislativa do Estado do Pará, 1991. Disponível em: http:// www.pge.pa.gov.br/sites/default/files/repositorio/1991/lo5703.pdf. Acesso em: 31 jul. 2019.

RICCEUR, Paul. A memória, a história, o esquecimento. Campinas: Editora Unicamp, 2007. 